\title{
Arm load magnitude affects selective shoulder muscle activation
}

\author{
Frans Steenbrink · Carel G. M. Meskers • \\ Bart van Vliet · Jorrit Slaman · H. E. J. Veeger • \\ Jurriaan H. De Groot
}

Received: 8 July 2008/Accepted: 11 March 2009/Published online: 7 April 2009

(C) The Author(s) 2009. This article is published with open access at Springerlink.com

\begin{abstract}
For isometric tasks, shoulder muscle forces are assumed to scale linearly with the external arm load magnitude, i.e., muscle force ratios are constant. Inverse dynamic modeling generally predicts such linear scaling behavior, with a critical role for the arbitrary load sharing criteria, i.e., the "cost function". We tested the linearity of the relation between external load magnitude exerted on the humerus and shoulder muscle activation. Six isometric force levels ranging from 17 to $100 \%$ of maximal arm force were exerted in 24 directions in a plane perpendicular to the longitudinal axis of the humerus. The direction of maximum muscle activation, the experimentally observed so called Principal Action (PA), was determined for each force magnitude in 12 healthy subjects. This experiment was also simulated with the Delft Shoulder and Elbow Model (DSEM) using two cost functions: (1) minimizing muscle stress and (2) a compound, energy related cost function. $\mathrm{PA}$, both experimental $\left(\mathrm{PA}_{\exp }\right)$ and simulated $\left(\mathrm{PA}_{\text {sim }}\right)$, was expected not to change with arm forces magnitudes. $\mathrm{PA}_{\exp }$ of the $\mathrm{mm}$. trapezius pars descendens, deltoideus pars medialis and teres major
\end{abstract}

F. Steenbrink $(\varangle)$ - C. G. M. Meskers · J. H. De Groot Laboratory for Kinematics and Neuromechanics, Departments of Orthopaedics and Rehabilitation Medicine, Leiden University Medical Center, Leiden, The Netherlands e-mail: f.steenbrink@lumc.nl

B. van Vliet · J. Slaman · H. E. J. Veeger Department of Human Movement Sciences, Institute of Fundamental and Clinical Human Movement Sciences, Vrije Universiteit Amsterdam, Amsterdam, The Netherlands

H. E. J. Veeger

Department of Biomechanical Engineering, Faculty of Mechanical, Maritime and Materials Engineering, Delft University of Technology, Delft, The Netherlands changed substantially as a function of external force magnitude, indicating external load dependency of shoulder muscle activation. In DSEM simulations, using the stress cost function, small non-linearities in the muscle forceexternal load dependency were observed, originating from gravitational forces working on clavicular and scapular bone masses. More pronounced non-linearities were introduced by using the compound energy related cost function, but no similarity was observed between $\mathrm{PA}_{\exp }$ and $\mathrm{PA}_{\text {sim. }}$.

Keywords Muscle coordination · Principal Action · Shoulder modeling

\section{Introduction}

Individual muscle forces change with armload direction. This load direction dependency was used to study muscle coordination in healthy subjects $[1,4,10,14,18]$ and subjects with shoulder pathologies $[5,20]$. The Principal Action (PA), which comprehends load direction dependent electromyography (EMG) parameters [4, 14], is used as a descriptive parameter for muscle coordination. In practice, repeated measurements are performed before and after an intervention, while maximum force around the shoulder may be altered by the intervention, e.g., by pain reduction or muscle tendon transfers [20]. In the comparison of these experiments, we assume that muscle forces scale linearly with external force magnitude. External forces may differ considerably in pre-post measurements $[5,20]$ and interindividually $[4,18]$. So linearity is a pre-requisite, or should be predictable if muscle contraction patterns are to be compared under these different loading conditions. In the jaw, linear scaling of muscle activity (EMG) and external load was indeed demonstrated [2, 25]. However, 
non-linear muscle activation scaling with external arm load was reported in the upper extremity [8].

In shoulder inverse dynamic modeling, linearity is generally assumed and incorporated in the load sharing criteria that are needed to mathematically solve the redundancy problem in order to reach a unique muscle activation pattern [3, 7-9, 21]. Praagman et al. [19] introduced a combination of a linear stress and a quadratic energy cost function, which turned out to fit best with non-linear in vivo obtained muscle energy expenditure around the elbow using near infrared spectroscopy. They stated that most cost functions are chosen rather arbitrary, mainly due to the fact that validation is difficult since muscle force cannot be measured accurately in vivo. The EMG based PA method offers an alternative method to compare in vivo observed activation simulated muscle activation, in order to interpret the experimental results and to predict possible load dependencies of shoulder muscle activation patterns in future studies [3, 4].

In the present study, we experimentally test the assumption that relative shoulder muscle forces do not change with armload magnitude. The experiment was numerically simulated, using the Delft Shoulder and Elbow Model (DSEM) with both a linear and an energy related cost function [19, 22-24]. We used the PA, i.e. the direction of maximum muscle activation assessed by either EMG (experiment) or force (simulation), respectively $\mathrm{PA}_{\exp }$ and $\mathrm{PA}_{\text {sim, as a }}$ parameter for muscle coordination.

\section{Methods}

\subsection{Subjects}

Twelve healthy subjects (five female; three left handed) with a mean age of 26 (SD 2.9 years) took part in the study.
The local medical ethical committee granted permission and all subjects gave informed consent.

\subsection{Experimental setup}

Subjects were seated with the dominant arm in a splint with the elbow in $90^{\circ}$ of flexion (Fig. 1). The set-up allowed for static, isometric contractions of shoulder muscles while loading the arm with a force of different magnitudes in different directions in a plane perpendicular to the humerus [3, 4, 18]. The humeral plane of elevation was approximately $60^{\circ}$ rotated externally from the para-sagittal plane and the humerus was $60^{\circ}$ abducted. The forearm was $45^{\circ}$ externally rotated relative to the horizontal plane (see Fig. 1). The objective of the set-up was to record only forces perpendicular to the longitudinal axis of the humerus. In rest, the arm was fully supported by means of a weight and pulley system to compensate for all gravitational forces and moments [4, 18]. The arm splint was attached to a 3D force transducer (AMTI-300, Advanced Mechanical Technology, Inc., Watertown MA, USA) by means of a low friction ball and socket joint. The transducer was mounted on a low friction rail in line with the humerus. This construction allowed for movement of the arm along four degrees of freedom (three rotations and a translation), while translations along the axes perpendicular to the humerus long arm were constrained. These forces controlled the position of a cursor on a computer screen placed in front of the subjects [4, 18] (Fig. 1).

EMG activity of 12 shoulder muscles was recorded (Table 1), and off-line post-processed [4, 18]. Nine shoulder muscles were recorded with the use of bipolar silver bar surface electrodes (DelSys, Bagnoli-16, Boston MA, USA, analog filter: $20 \mathrm{~Hz}$ high pass, $450 \mathrm{~Hz}$ low pass, $10 \mathrm{~mm}$ electrode length, inter-electrode distance of $10 \mathrm{~mm}$ ).
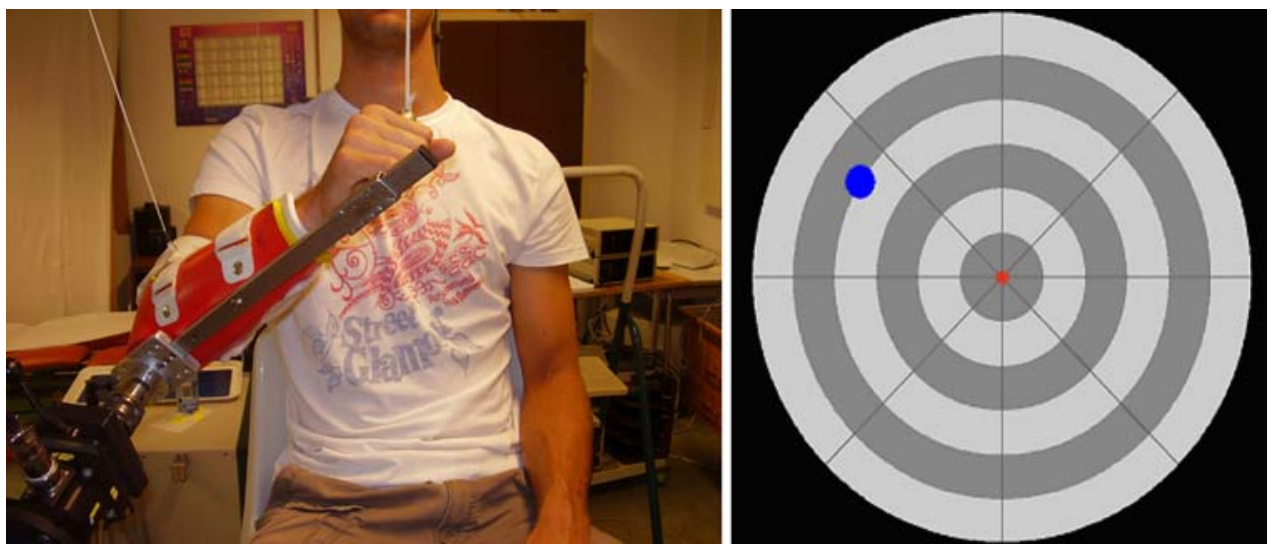

Fig. 1 Experimental setup (left panel) and visual feedback (right panel); the subject had the arm in a splint, which was connected to a force transducers. Subjects were required to bring the arm force driven red cursor into the blue target area. The force, perpendicular to the humerus long axis, was recorded with a 6-dof force transducer (AMTI). The target indicated force direction $(n=24)$ and force magnitude, i.e., radius $(n=6)$, resulting in 144 combinations 
Table 1 Experimentally recorded shoulder muscles, localization of the electrodes and type of applied electrodes (similar to [4, 18] for comparison)

\begin{tabular}{|c|c|c|}
\hline Muscle & Electrode position & Electrode type \\
\hline m. supraspinatus & $\begin{array}{l}2 / 3 \text { line trigonum spinae-angulus acromialis } \\
2 \mathrm{~cm} \text { above spinal ridge }\end{array}$ & Wire \\
\hline m. infraspinatus & $10 \mathrm{~cm}$ below insertion site supraspinatus & Wire \\
\hline m. subscapularis & $\begin{array}{l}\text { Halfway line angulus inferior trigonum } \\
\text { spinae, underneath margo medialis }\end{array}$ & Wire \\
\hline m. trapezius pars descendens & $\begin{array}{l}2 / 3 \text { on the line seventh cervical vertebra } \\
\text { trigonum spinae }\end{array}$ & Surface \\
\hline m. trapezius pars ascendens & $\begin{array}{l}\text { Between the trigonum spinae and the eight } \\
\text { thoracic dorsal spine, } \\
\text { well above the caudal muscle ridge }\end{array}$ & Surface \\
\hline m. deltoideus pars anterior & $\begin{array}{l}\text { Middle of muscle belly, anterior part } \mathrm{m} \text {. } \\
\text { deltoideus }\end{array}$ & Surface \\
\hline m. deltoideus pars medialis & $\begin{array}{l}\text { Middle of muscle belly, medial part m. } \\
\text { deltoideus }\end{array}$ & Surface \\
\hline m. deltoideus pars posterior & $\begin{array}{l}\text { Middle of muscle belly, posterior part } \mathrm{m} \text {. } \\
\text { deltoideus }\end{array}$ & Surface \\
\hline m. serratus anterior & Sixth head below angulus inferior scapulae & Surface \\
\hline m. teres major & Middle of muscle belly & Surface \\
\hline $\mathrm{m}$. pectoralis major pars clavicularis & $\begin{array}{l}\text { Middle of muscle belly, clavicular part } \mathrm{m} \text {. } \\
\text { pectoralis major }\end{array}$ & Surface \\
\hline m. latisimuss dorsi & $6 \mathrm{~cm}$ below angulus inferior scapulae & Surface \\
\hline
\end{tabular}

Sample rate of analog filtered EMG and force data was $1,000 \mathrm{~Hz}$. Before placement of the electrodes, the skin was abraded, cleaned and a skin preparation gel (Skin Pure, Nihon Kohden) was used. The EMG of the three rotatorcuff muscles was recorded by means of bi-polar wire electrodes (Table 1). The wires were made of Teflon coated stainless steel with bare tips of 2-mm length and were inserted with a sharp hollow needle. The electrode tips were bent in a sharp angle, so that after withdrawal of the needles, the wires would remain in situ. The wires for the m. subscapularis were inserted with a curved needle underneath the medial border of the scapula [12]. Before insertion of the needles, the skin was anaesthetized with a $5 \%$ lidocaine solution. The needles for the mm. subscapularis and infraspinatus were inserted until the scapular bone was touched.

\subsection{Protocol}

In the experimental setup, the force task existed of moving a (red) cursor, driven by the forces exerted perpendicular to the longitudinal axis of the upper arm on the force transducer, into a (blue) target area (Fig. 1). Size of the target area was a predetermined area with a range of three times standard deviation (SD), determined from measurements on two subjects. Before the experiment started, the subject's maximum force target magnitude $\left(F_{\max }\right)$ that could be maintained in all 24 directions was determined. Subsequently, six force levels were applied equidistantly, covering a range from 17 to $100 \%$ of $F_{\max }$. The force driven cursor was to be held within the target area for $2 \mathrm{~s}$, while the target randomly indicated 24 directions (angle) at 6 force magnitudes (radius), resulting in 144 combinations. Between the trials, ample rest of at least $5 \mathrm{~s}$ was given in order to avoid too much fatigue effects. Subsequently, the PA at each force magnitude could be determined off-line $[4,18]$.

\subsection{Data post-processing}

EMG recordings were full-wave rectified and filtered for visual inspection (3rd order recursive low pass Butterworth at $10 \mathrm{~Hz}$ ). The $2 \mathrm{~s}$ 'in target' full-wave rectified EMG was averaged and rest level EMG was subtracted. For each of six force levels, the averaged rectified EMG was normalized with respect to the maximum EMG for the appropriate force level. Subsequently, a parameterized least squares curve was estimated through the 24 EMG values to obtain one direction of maximal EMG activity or Principal Action $\left(\mathrm{PA}_{\mathrm{exp}}\right)$ [4] for every muscle at each force level. Outliers and inaccurate estimations of the $\mathrm{PA}_{\text {exp }}$ were selected and removed by two investigators when consensus was achieved.

\subsection{Statistical analysis}

EMG data were collected for $n=12$ subjects, $n_{m}=12$ muscles, 24 force directions and $n_{f}=6$ force levels. We 
tested the H0-hypothesis that muscle coordination did not change under different load magnitudes, i.e., $\mathrm{PA}_{\mathrm{exp}}$ of each muscle over the six force levels was constant. For each individual muscle a regression line, describing the PA of that muscle as a function of force magnitude, was estimated. Subsequently, the slope coefficient of this line $(\beta)$ was tested not to differ from zero.

\subsection{Model simulations}

The experiment was simulated by inverse dynamic numeric modeling using the DSEM [22, 24]. Kinematical input (arm position) was determined using 3D kinematical recording of one subject mounted in the experimental setup using an electromagnetic tracking device [15]. The ISG standardization protocol for the upper extremity including regression based GH-estimation $[16,26]$ was used. A pointer was used to digitize 14 bony-landmarks with respect to sensors mounted on the thorax, the acromion [13], the upper arm and the forearm. The subjects arm with the sensors attached was positioned into the splint and subsequently the position was recorded. All DSEM simulations were performed using this single position and an external force applied at the elbow in 24 directions at 6 force levels of the model's $F_{\max }$, exactly simulating the experiment. In order to simulate the weight compensation on the arm in the experiments, gravity working on the humerus in the model was set to zero. By means of inverse dynamic simulation, muscle forces required to satisfy both the mechanical force equilibrium and moment equilibrium were calculated. Two different load sharing criteria were applied: a stress cost function, i.e., minimization of summed squared muscle stresses, and a compound linear and quadratic energy cost function [19]. Based on the estimated muscle forces, the Principal Actions for the muscles in the DSEM were calculated $\left(\mathrm{PA}_{\text {sim }}\right)[3,4]$.

\section{Results}

The average maximum force performed within the study population was $65 \mathrm{~N}(\mathrm{SD}=22.3)$. $\mathrm{PA}_{\exp }$ for all muscles and loading conditions, as well as the number of observations after exclusion of outliers, is presented in Table 2. $\mathrm{Mm}$. trapezius pars descendens, deltoideus pars medialis and teres major showed a significant shift of $\mathrm{PA}_{\exp }$ as a function of external load. The maximum observed effect (m. teres major) of external loading on $\mathrm{PA}_{\exp }$ was $\beta=$ -1.08 , i.e. $-1.08^{\circ}$ per $\%$ of $F_{\max }$. The $\mathrm{PA}_{\exp }$ dependency was described by a linear regression model (Table 3 ).

In Fig. 2 changes in PA with respect to PA at the first force level (PA at $17 \%$ of $F_{\max }=0^{\circ}$ ) are presented. $\mathrm{PA}_{\exp }$ are shown (blue circles), together with $\mathrm{PA}_{\text {sim }}$, obtained using both a quadratic stress cost function (green upward- pointing triangles) and a compound energy cost function (black downward-pointing triangles). DSEM simulations with a quadratic stress cost function showed very small, but noticeable non-linear scaling. In our model, we simulated gravity compensation of the humerus, but the observed non-linearities could still be introduced by gravity working on the clavicle and scapular bone, which was obviously not controlled for in the in vivo experiments. To make this effect more clearly visible, we performed model simulations including only one force direction, i.e., a force acting downwards on the arm, with two different magnitudes, i.e., 10 and $20 \mathrm{~N}$. We subsequently compared estimated muscle forces in a model with gravity working on the clavicle and scapular bone masses, and a model without. Indeed, we found non-linear external load dependence introduced in the first model in contrast to the simulation with full gravity compensation (Table 4).

The compound 'energy cost function' appeared to result in a non-linear relation between $\mathrm{PA}_{\text {sim }}$ and external load. Except for the $\mathrm{m}$. supraspinatus no similarity was observed between $\mathrm{PA}_{\text {exp }}$ and $\mathrm{PA}_{\text {sim }}$ (Fig. 2).

\section{Discussion}

Activation of three shoulder muscles appeared to be load dependent. This has consequences for the interpretation of muscle contraction patterns as measured in patients with shoulder disorders before and after intervention. In shoulder model simulations (DSEM) of the present experiment, non-linearities in the muscle force-external load relationships were not found using a quadratic stress cost function except when gravitational forces working on clavicular and scapular bone mass were incorporated. More pronounced non-linearities were introduced using a compound energy related cost function, however not leading to a better resemblance of $\mathrm{PA}_{\text {exp }}$ to $\mathrm{PA}_{\text {sim }}$.

\subsection{Comparison with previous research}

Only a few studies assessed load dependency of muscles in vivo. In a previous study by Meskers et al. [17], external load dependency of shoulder muscle activation was found during a similar multi-directional task using a similar EMG processing method. In that study, clockwise shifts of $\mathrm{m}$. deltoideus pars medialis $\left(60^{\circ}\right)$ and counter clockwise shifts of mm. serratus anterior $\left(6^{\circ}\right)$ and $\mathrm{m}$. latissimus dorsi $\left(20^{\circ}\right)$ were found. However, in contrast to the present study: (1) fixed force levels were used without normalizing, meaning that subjects were measured at different percentages of $F_{\max }$; (2) the external loads and force angles were not applied in randomized order, which might introduce muscle activation dependent recruitment bias and fatigue 
Table 2 Average Principal Action $\mathrm{PA}_{\exp }(\mathrm{SD})$ for six relative force levels and $n$ observations

\begin{tabular}{|c|c|c|c|c|c|c|}
\hline \multirow[t]{2}{*}{ Muscle } & \multicolumn{6}{|c|}{ Mean $\mathrm{PA} \pm \mathrm{SD}\left({ }^{\circ}\right)$} \\
\hline & $17\left(\% F_{\max }\right)$ & $33\left(\% F_{\max }\right)$ & $50\left(\% F_{\max }\right)$ & $67\left(\% F_{\max }\right)$ & $83\left(\% F_{\max }\right)$ & $100\left(\% F_{\max }\right)$ \\
\hline \multirow[t]{2}{*}{ m. supraspinatus } & $35.03(50.89)$ & $15.98(32.11)$ & $35.91(56.29)$ & $43.03(56.00)$ & $42.14(58.23)$ & $41.18(50.35)$ \\
\hline & $N=8$ & $N=9$ & $N=11$ & $N=9$ & $N=9$ & $N=10$ \\
\hline \multirow[t]{2}{*}{ m. infraspinatus } & $6.12(44.32)$ & $20.95(24.74)$ & $17.81(30.65)$ & $15.97(25.75)$ & $20.56(24.23)$ & $22.62(28.02)$ \\
\hline & $N=8$ & $N=9$ & $N=11$ & $N=11$ & $N=12$ & $N=12$ \\
\hline \multirow[t]{2}{*}{ m. subscapularis } & 164.15 (71.34) & $147.63(84.12)$ & $146.26(76.61)$ & $152.36(79.62)$ & $149.84(75.11)$ & $154.10(87.99)$ \\
\hline & $N=8$ & $N=9$ & $N=10$ & $N=10$ & $N=11$ & $N=10$ \\
\hline \multirow[t]{2}{*}{ m. trapezius pars descendens } & $16.05(34.53)$ & $11.68(35.73)$ & $22.62(29.69)$ & $30.90(32.77)$ & $36.00(28.99)$ & $44.79(26.82)$ \\
\hline & $N=9$ & $N=11$ & $N=12$ & $N=12$ & $N=12$ & $N=12$ \\
\hline \multirow[t]{2}{*}{ m. trapezius pars ascendens } & $93.70(82.84)$ & $56.7(54.82)$ & $79.76(74.74)$ & $84.57(55.73)$ & $65.51(46.30)$ & $80.73(69.66)$ \\
\hline & $N=9$ & $N=11$ & $N=12$ & $N=12$ & $N=12$ & $N=12$ \\
\hline \multirow[t]{2}{*}{ m. deltoideus pars anterior } & $6.46(49.70)$ & $-14.87(7.76)$ & $-19.09(12.93)$ & $-6.41(16.20)$ & $-6.75(18.27)$ & $-1.99(25.04)$ \\
\hline & $N=8$ & $N=10$ & $N=12$ & $N=12$ & $N=12$ & $N=12$ \\
\hline \multirow[t]{2}{*}{ m. deltoideus pars medialis } & $60.05(23.95)$ & $62.93(21.73)$ & $67.83(22.44)$ & $68.71(21.99)$ & $68.95(18.89)$ & $73.02(19.82)$ \\
\hline & $N=10$ & $N=11$ & $N=12$ & $N=12$ & $N=12$ & $N=12$ \\
\hline \multirow[t]{2}{*}{ m. deltoideus pars posterior } & $92.52(16.44)$ & $89.23(14.24)$ & $91.17(9.14)$ & $91.23(9.80)$ & $91.82(16.58)$ & $93.54(11.97)$ \\
\hline & $N=9$ & $N=10$ & $N=11$ & $N=11$ & $N=11$ & $N=11$ \\
\hline \multirow[t]{2}{*}{ m. serratus anterior } & $300.52(59.69)$ & $300.76(49.82)$ & $306.48(63.58)$ & $319.67(68.83)$ & $316.23(68.49)$ & $313.61(61.88)$ \\
\hline & $N=5$ & $N=9$ & $N=12$ & $N=12$ & $N=12$ & $N=12$ \\
\hline \multirow[t]{2}{*}{ m. teres major } & $218.81(54.20)$ & $203.97(69.23)$ & $201.64(66.61)$ & $175.08(57.08)$ & $178.56(56.70)$ & $172.62(57.39)$ \\
\hline & $N=8$ & $N=12$ & $N=12$ & $N=12$ & $N=12$ & $N=12$ \\
\hline \multirow[t]{2}{*}{ m. pectoralis major pars clavicularis } & $265.81(49.34)$ & $292.98(26.85)$ & $277.37(27.30)$ & $255.15(67.93)$ & $253.37(63.18)$ & $250.19(66.34)$ \\
\hline & $N=12$ & $N=11$ & $N=12$ & $N=12$ & $N=12$ & $N=12$ \\
\hline \multirow[t]{2}{*}{ m. latisimuss dorsi } & $158.71(38.52)$ & $153.80(18.34)$ & $151.68(25.00)$ & $137.14(18.38)$ & $155.69(43.95)$ & $146.44(22.45)$ \\
\hline & $N=7$ & $N=10$ & $N=10$ & $N=11$ & $N=10$ & $N=9$ \\
\hline
\end{tabular}

Outliers were excluded resulting in different numbers of observations $(N)$

Table 3 Linear regression slope parameters for the $\mathrm{PA}_{\exp }$ to external load and their $P$ values

\begin{tabular}{lcl}
\hline Muscle & Linear component $\mathrm{PA}_{\exp }(\beta)$ & $P$ \\
\hline m. supraspinatus & 0.1995 & 0.181 \\
m. infraspinatus & 0.1362 & 0.515 \\
m. subscapularis & 0.1897 & 0.322 \\
m. trapezius pars descendens & 0.3857 & $0.005^{*}$ \\
m. trapezius pars ascendens & -0.0283 & 0.619 \\
m. deltoideus pars anterior & 0.1172 & 0.156 \\
m. deltoideus pars medialis & 0.1436 & $0.004^{*}$ \\
m. deltoideus pars posterior & 0.0222 & 0.405 \\
m. serratus anterior & 0.2143 & 0.400 \\
m. teres major & -1.0804 & $0.001 *$ \\
m. pectoralis major pars & -0.3543 & 0.230 \\
\multicolumn{1}{c}{ clavicularis } & & \\
m. latisimuss dorsii & -0.1204 & 0.286 \\
\hline
\end{tabular}

Positive values represent a clockwise shift of the $\mathrm{PA}_{\exp }$

* Significant differences at $P<0.05$

effects at the higher load tasks; (3) the positioning of the subjects in the present study was slightly different, i.e., the elevation angle was $15^{\circ}$ lower.
Recruitment of muscles as a function of external load was studied on jaw muscles using a similar technique of relating EMG activity to increasing external forces [2, 22]. With increasing external forces, linear EMG-external force relationships where found for each jaw muscle (part). It was concluded that an increase in activity is achieved by the same, simultaneous increase in excitation activity. This would consequently imply a load independent PA direction. Praagman et al. [19] also reported linear scaling of muscle forces with external loading around the elbow by means of biomechanical model simulation using DSEM and muscle energy expenditure using near infrared spectroscopy. Possible explanations of the discrepancy of the present study with previous work are that with 24 force directions in a full circle around the humerus, the resolution in the present study was considerable higher than in aforementioned studies.

\subsection{Clinical consequences}

In clinical settings, data are not acquired at different magnitudes of external force but at (near) maximum MVC 
Fig. 2 Changes in PA with respect to $\mathrm{PA}$ at the first force level (PA at $17 \%$ of $F_{\max }=0^{\circ}$ ); $\mathrm{PA}_{\exp }$ (blue circles) and $\mathrm{PA}_{\text {sim }}$ with bone masses of the scapula and clavicle (stress cost function, green upwardpointing triangles; energy cost function, black downwardpointing triangles). $\mathrm{PA}_{\exp }$ shows significant non-linear relation to external loading for $\mathrm{mm}$ trapezius descendens, deltoideus anterior and teres major. $\mathrm{PA}_{\text {sim }}$ with the energy cost function and in lesser degree the stress cost function show a non-linear relation with external loading. $\mathrm{PA}_{\text {sim }}$ of $\mathrm{m}$. deltoideus medialis is lacking because the deltoids in the DSEM are divided in a clavicular part (represented by the $\mathrm{m}$. deltoideus anterior) and a scapular part (represented by the m. deltoid posterior)
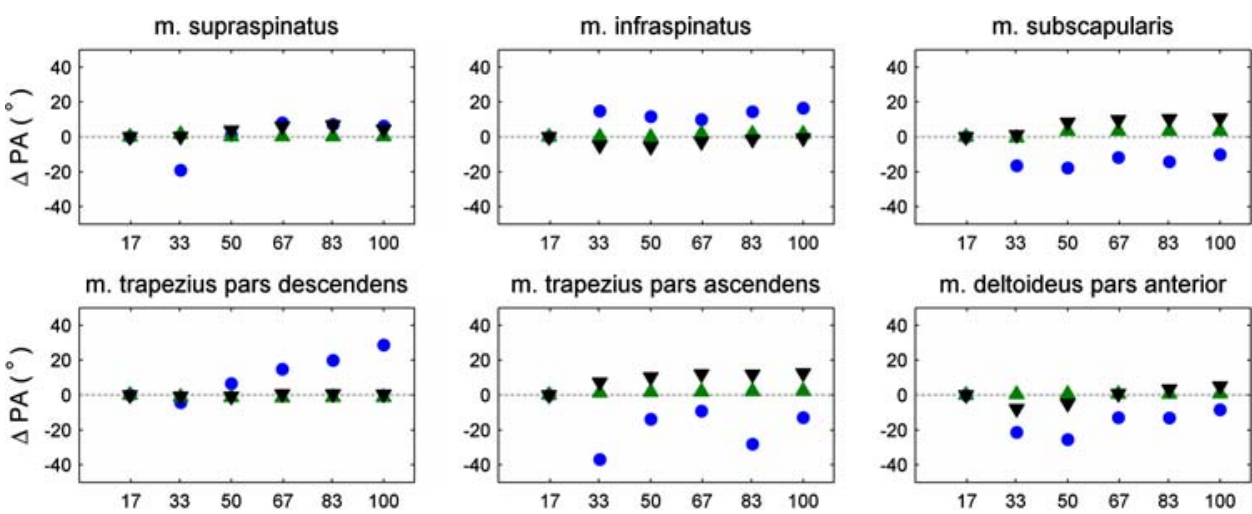

$\mathrm{m}$. trapezius pars ascendens

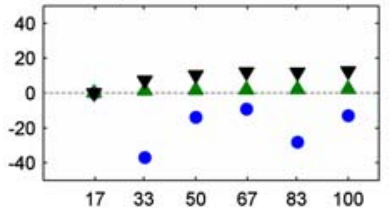

$\mathrm{m}$. deltoideus pars anterior

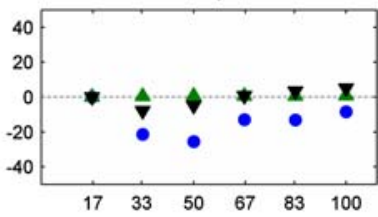

$\mathrm{m}$. deltoideus pars medialis

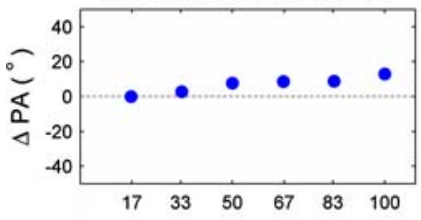

$\mathrm{m}$. deltoideus pars posterior

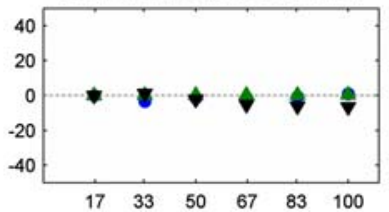

m. pectoralis major pars clav.
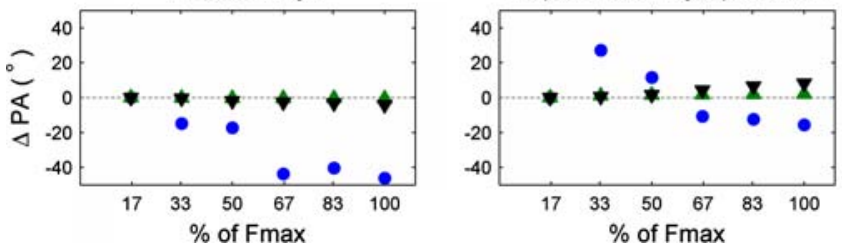

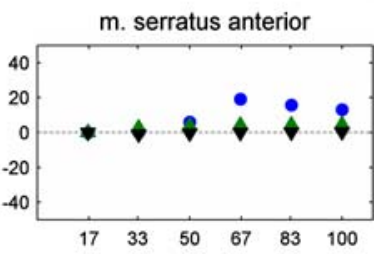

m. latissimus dorsi

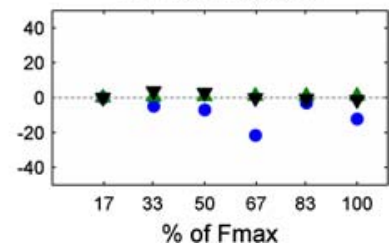

Table 4 By DSEM simulations estimated muscle forces using the stress cost criteria, without $(\mathrm{Fg}-)$ and with $(\mathrm{Fg}+)$ taking mass of clavicula $(0.156 \mathrm{~kg})$ and scapula $(0.705 \mathrm{~kg})$ [22] into account at a vertical downwards directed external load of 10 and $20 \mathrm{~N}$, respectively

\begin{tabular}{|c|c|c|c|c|}
\hline \multirow[t]{3}{*}{ Muscle } & \multicolumn{4}{|c|}{ Muscle forces (N) } \\
\hline & \multicolumn{2}{|l|}{$\mathrm{Fg}-$} & \multicolumn{2}{|l|}{$\mathrm{Fg}+$} \\
\hline & $10 \mathrm{~N}$ & $20 \mathrm{~N}$ & $10 \mathrm{~N}$ & $20 \mathrm{~N}$ \\
\hline m. supraspinatus & 15.72 & 3.44 & 1.70 & 3.32 \\
\hline m. infraspinatus & 23.81 & 47.62 & 24.69 & 48.66 \\
\hline m. subscapularis & 10.67 & 21.34 & 10.47 & 21.10 \\
\hline m. trapezius pars descendens & 8.06 & 16.12 & 13.21 & 21.48 \\
\hline m. trapezius pars ascendens & 2.71 & 5.42 & 3.41 & 6.04 \\
\hline m. deltoideus pars anterior & 12.95 & 25.90 & 13.09 & 26.07 \\
\hline m. deltoideus pars posterior & 0.87 & 1.74 & 2.08 & 3.17 \\
\hline m. serratus anterior & 15.53 & 31.06 & 19.42 & 34.80 \\
\hline m. teres major & 0 & 0 & 0 & 0 \\
\hline $\mathrm{m}$. pectoralis major pars clavicularis & 10.28 & 20.56 & 11.93 & 22.50 \\
\hline m. latisimuss dorsi & 0 & 0 & 0 & 0 \\
\hline
\end{tabular}

Note that without gravity muscle forces scale linear (exact duplication of estimated muscle force with twice the external load), while nonlinearities are introduced with gravity

$[5,20]$. Thus, influences of external loading, cross talk and PA estimation accuracy were presumed to be minimal. The maximum force a patient can exert will generally change as a result of therapeutic interventions. In patients it is therefore recommended to acquire PA data at equal percentages of their $F_{\text {max }}$.

The maximum effect of external loading on PA will not exceed $1.08^{\circ}$ per percentage of MVC or Newton, resulting in $16^{\circ} \mathrm{PA}$ shift for an external force change of $15 \mathrm{~N}$ for $\mathrm{m}$. teres major. In pre- and post-intervention comparisons, this is in the range of the inter-subject standard deviation and is substantially less than, e.g., observed in patients with massive cuff tears where shifts for $m$. teres major increased $75^{\circ}[5,20]$. These large PA changes observed in patients cannot be explained by external force dependency, but are obviously pathology dependent.

\subsection{DSEM: load sharing criteria}

The applied load-sharing functions either constrain or introduce non-linear scaling. The quadratic stress minimization allows synergy between agonist muscles more than linear criterions [7]. The energy-related cost function with a linear and quadratic component was previously shown to lead to more realistic predictions of muscle activation [19] for elbow-forearm external force tasks. Simulating the present experiment with the compound energy related criterion indeed predicted a non-linear external loaddependent muscle contraction, resulting in a better $\mathrm{PA}_{\text {ext }}$ to $\mathrm{PA}_{\text {sim }}$ resemblance for the $\mathrm{mm}$. supraspinatus and, at least for the contour also for the m. deltoideus anterior. However, 
there was no resemblance for the remaining majority of muscles, implying that model simulations do not predict the observed effects in the experiment. In vivo we might apply alternative control strategies that are not caught adequately by the mechanical modeling and load sharing criteria. Additionally, force magnitude and direction induced changes of clavicle and scapula orientation may not be neglected, and should thus experimentally be controlled for, or incorporated in the simulations.

\subsection{DSEM: gravitational loads}

Introduction of gravitational forces resulted in non-linear muscle force-external load relations when the stress cost function was used, especially for the low loading conditions. Gravitation generates constant joint-torques that requires constant muscle force compensation. This baseline muscle loading interacts with the linear increasing external component, resulting in a non-linear appearance. Where bone masses will not be much of a factor, muscle masses probably will. Muscle masses and the application point of gravitational forces on the different muscle volumes are presently not adequately incorporated in the DSEM. Variations in the gravity forces-external load ratio could explain differences of the present findings with respect to the previous studies to some extent [2, 17, 19, 25]. It is recommended to take gravitational forces into account in model simulations, especially when the direction of the external force does not coincide with the direction of the vertical gravitational forces and the moment arms of external force directions are changing.

\subsection{Possible error sources in the present experiment}

The validity of the EMG model as used in the present study is extensively discussed [4, 18]. When external force is increased, the signal over noise ratio will increase which will lead to optimal estimates of $\mathrm{PA}_{\text {exp }}$. Therefore, $\mathrm{PA}_{\mathrm{exp}}$ estimations at low forces have reduced accuracy. However, it is unlikely that this phenomenon explains the present findings as shifts of PA are not limited to the lower loading conditions.

Influence of cross talk might also be external load dependent. However, PA is estimated at the peak of muscle activation and therefore the PA method as such can be considered relatively insensitive to cross talk, even at the lower external loads.

During the experiments, the gross position of the subjects was kept constant and special care was taken that subjects could not cheat to be able to meet the higher external forces. Small scapula positional changes could, however, not be ruled out and because external load direction dependent scapular positions were previously observed [6], these changes are likely to increase with increasing external load magnitude influencing muscle moment arms around the SC, $\mathrm{AC}$ and GH joints, which affect the PA direction. To what extent PA's change as a function of scapular position changes requires further research.

Open Access This article is distributed under the terms of the Creative Commons Attribution Noncommercial License which permits any noncommercial use, distribution, and reproduction in any medium, provided the original author(s) and source are credited.

\section{References}

1. Arwert HJ, de Groot JH, van Woensel WW, Rozing PM (1997) Electromyography of shoulder muscles in relation to force direction. J Should Elb Surg 6:360-370. doi:10.1016/S10582746(97)90004-5

2. Blanksma NG, Van Eijden TM, Weijs WA (1992) Electromyographic heterogeneity in the human masseter muscle. J Dent Res 71:47-52

3. de Groot JH (1989) The shoulder; a kinematic and dynamic analysis of motion and loading. PhD thesis, Delft University of Technology, Delft, The Netherlands. ISBN: 90-9011298-7

4. de Groot JH, Rozendaal LA, Meskers CGM, Arwert HJ (2004) Isometric shoulder muscle activation patterns for 3-D planar forces: a methodology for musculo-skeletal model validation. Clin Biomech (Bristol, Avon) 19:790-800. doi:10.1016/j. clinbiomech.2004.05.013

5. de Groot JH, van de Sande MA, Meskers CG, Rozing PM (2006) Pathological teres major activation in patients with massive rotator cuff tears alters with pain relief and/or salvage surgery transfer. Clin Biomech (Bristol, Avon) 21(Suppl 1):S27-S32. doi: 10.1016/j.clinbiomech.2005.09.011

6. de Groot JH, van Woensel W, van der Helm FC (1999) Effect of different arm loads on the position of the scapula in abduction postures. Clin Biomech (Bristol, Avon) 14:309-314. doi: 10.1016/S0268-0033(98)90094-8

7. Happee R (1994) Inverse dynamic optimization including muscular dynamics, a new simulation method applied to goal directed movements. J Biomech 27(7):953-960. doi:10.1016/0021-9290 (94)90267-4

8. Happee R, van der Helm FC (1995) The control of shoulder muscles during goal directed movements, an inverse dynamic analysis. J Biomech 28(10):1179-1191. doi:10.1016/0021-9290 (94)00181-3

9. Dul J, Townsend MA, Shiavi R, Johnson GE (1984) Muscular synergism-I. On criteria for load sharing between synergistic muscles. J Biomech 17:663-673. doi:10.1016/0021-9290(84) 90120-9

10. Flanders M, Soechting JF (1990) Arm muscle activation for static forces in three-dimensional space. J Neurophysiol 64:1818-1837

11. Hogfors C, Sigholm G, Herberts P (1987) Biomechanical model of the human shoulder-I. Elements. J Biomech 20:157-166. doi: 10.1016/0021-9290(87)90307-1

12. Kadaba MP, Cole A, Wootten ME, McCann P, Reid M, Mulford P, April E, Bigliani L (1992) Intramuscular wire electromyography of the subscapularis. J Orthop Res 10:394-397. doi: 10.1002/jor.1100100312

13. Karduna AR, McClure PW, Michener LA, Sennett B (2001) Dynamix measurements of three-dimensional scapular kinematics: a validation study. J Biomech Eng 123:184-190. doi: $10.1115 / 1.1351892$

14. Laursen B, Jensen BR, Nemeth G, Sjogaard G (1998) A model predicting individual shoulder muscle forces based on relationship 
between electromyographic and 3D external forces in static position. J Biomech 31:731-739. doi:10.1016/S0021-9290(98) 00091-8

15. Meskers CG, Vermeulen HM, de Groot JH, van der Helm FC, Rozing PM (1998) 3D shoulder position measurements using a six-degree-of-freedom electromagnetic tracking device. Clin Biomech (Bristol, Avon) 13:280-292. doi:10.1016/S0268-0033 (98)00095-3

16. Meskers CG, van der Helm FC, Rozendaal LA, Rozing PM (1989) In vivo estimation of the glenohumeral joint rotation center from scapular bony landmarks by linear regression. J Biomech 31:93-96. doi:10.1016/S0021-9290(97)00101-2

17. Meskers CGM (1989) Quantitative assessment of shoulder function in a clinical setting: methodological aspects and applications. PhD thesis, Leiden University Medical Center, Leiden, The Netherlands

18. Meskers CGM, de Groot JH, Arwert HJ, Rozendaal LA, Rozing PM (2004) Reliability of force direction dependent EMG parameters of shoulder muscles for clinical measurements. Clin Biomech (Bristol, Avon) 19:913-920. doi:10.1016/j.clinbiomech. 2004.05.012

19. Praagman M, Chadwick EK, van der Helm FC, Veeger HE (2006) The relationship between two different mechanical cost functions and muscle oxygen consumption. J Biomech 39:758765. doi:10.1016/j.jbiomech.2004.11.034

20. Steenbrink F, de Groot JH, Veeger HE, Meskers CG, van de Sande MA, Rozing PM (2006) Pathological muscle activation patterns in patients with massive rotator cuff tears, with and without subacromial anaesthetics. Man Ther 11:231-237. doi: 10.1016/j.math.2006.07.004

21. Tsirakos D, Baltzopoulos V, Bartlett R (1997) Inverse optimization: functional and physiological considerations related to the force-sharing problem. Crit Rev Biomed Eng 25:371-407

22. van der Helm FC (1994) A finite element musculoskeletal model of the shoulder mechanism. J Biomech 27:551-569. doi:10.1016/ 0021-9290(94)90065-5

23. van der Helm FC, Veeger HE, Pronk GM, van der Woude LH, Rozendal RH (1992) Geometry parameters for musculoskeletal modelling of the shoulder system. J Biomech 25:129-144. doi: 10.1016/0021-9290(92)90270-B

24. Van der Helm FCT (1997) A three-dimensional model of the shoulder and elbow. In: Veeger HEJ, van der Helm FCT, Rozing PM (eds) First conference of the international shoulder group. Shaker Publishers BV, Delft University of Technology, The Netherlands

25. van Eijden TM, Blanksma NG, Brugman P (1993) Amplitude and timing of EMG activity in the human masseter muscle during selected motor tasks. J Dent Res 72:599-606

26. Wu G, van der Helm FC, Veeger HE, Makhsous M, van Roy P, Anglin C, Nagels J, Karduna A, McQuade K, Wang X, Werner FW, Buchholz B (2005) ISB recommendation on definitions of joint coordinate systems of various joints for the reporting of human joint motion-Part II: shoulder, elbow, wrist and hand. J Biomech 38:981-992. doi:10.1016/j.jbiomech.2004.05.042 